\title{
APOLIPOPROTEIN E5 AND E7 IN APPARENTLY HEALTHY JAPANESE MALES: FREQUENCIES AND RELATION TO PLASMA LIPID LEVELS
}

\author{
Yasuko Yamanouchi, ${ }^{1,3}, *$ Tadao ARINami, ${ }^{1}$ Shigeru Tsuchiya, ${ }^{2}$ \\ Ryunosuke MiYazaki, ${ }^{4}$ Haruyoshi TaKaki, ${ }^{3}$ Takako TaKano, ${ }^{3}$ \\ and Hideo HamaGUCHI ${ }^{1}$ \\ ${ }^{1}$ Department of Medical Genetics, Institutes of Basic Medical Sciences, and \\ ${ }^{2}$ Department of Nursing and Rehabilitation Medicine, Institute of Social Medical Science, \\ University of Tsukuba, Tsukuba, Ibaraki 305, Japan \\ ${ }^{3 *}$ Department of Hygiene and Public Health, Teikyo University School of Medicine, \\ Kaga, Itabashi-ku, Tokyo 173, Japan \\ ${ }^{4} K u d a n z a k a$ Hospital, Chiyoda-ku, Tokyo 102, Japan
}

\begin{abstract}
Summary In order to determine the frequencies of apolipoproteins (apo) E5 and E7 and their relation to plasma lipid levels, apo E phenotypes were determined in 608 healthy Japanese male adults by two-dimensional gel electrophoresis. Apo E5 and E7 were observed in $2.8 \%$ of the subjects, in addition to the three common apo $\mathrm{E}$ isoforms, E2, E3, and E4. Apo E5 was divided into two subtypes based on the migration rate on SDS/PAGE, E5f is the type with faster migration and E5s slower migration. The gene frequencies were: the $\varepsilon 3$ allele, 0.841 ; the $\approx 4$ allele, 0.095 ; the $\varepsilon 2$ allele, 0.049 ; the $\varepsilon 7$ allele, 0.009 ; the $\varepsilon 5$ allele encoding apo E5f (the $\varepsilon 5 f$ allele), 0.004; and the $\varepsilon 5$ allele encoding apo E5s (the $85 \mathrm{~s}$ allele), 0.001. The five individuals with apo E5f and the eleven with apo E7 were heterozygotes and normocholesterolemic. Also plasma apo B and apo E levels were not increased in any subjects with apo E5f or apo E7. The data suggests that apo E5f and E7 are not rare in the Japanese population but that neither apo E5f nor E7 are associated with hypercholesterolemia in most of the heterozygotes.
\end{abstract}

Key Words apolipoprotein E5, apolipoprotein E7, apolipoprotein E (apo E) lipid level, hypercholesterolemia, allele frequency

Received February 25, 1994; Revised version accepted July 7, 1994.

*To whom correspondence should be addressed. 


\section{INTRODUCTION}

Apolipoprotein E (apo E) is a constituent of chylomicrons, chylomicron remnants, very-low-density lipoproteins (VLDL), intermediate-density lipoproteins (IDL), and high-density lipoproteins (HDL). It plays an important role in determining triglyceride-rich lipoprotein catabolism by mediating the cellular uptake of specific lipoproteins such as IDL and chylomicron remnants through an interaction with apo $\mathrm{B} / \mathrm{E}(\mathrm{LDL})$ receptors and distinct hepatic apo $\mathrm{E}$ receptors (Mahley, 1988). It has been shown that the deletion of apo $E$ and an apo $E$ variant which has no binding activity to the receptor, leads to hyperlipoproteinemia (HLP) type III (Utermann et al., 1977; Ghiselli et al., 1981).

Human plasma apo $\mathrm{E}$ is composed of 299 amino acid residues and has a calculated molecular weight of 34,200 . In plasma there are three common isoforms of apo $\mathrm{E}(\mathrm{E} 2, \mathrm{E} 3$, and $\mathrm{E} 4)$ which differ from each other in their charge by one unit and are detected by isoelectric focusing (IEF). Apo E3 is the most commonly occurring form. The apo E2 isoform, which has an Arg $\rightarrow$ Cys substitution at position 158, is associated with decreased plasma levels of total cholesterol (TC) and low-density lipoprotein-cholesterol (LDL-C). It has been shown that apo E2 has a decreased fractional catabolic rate and markedly impaired binding to the apo B/E receptor as compared to apo E3 (Gregg et al., 1981; Weisgraber et al., 1982; Rall et al., 1982), causing type III HLP in some homozygotes. On the other hand, the apo E4 isoform, which has a Cys $\rightarrow$ Arg substitution at position 112, is associated with elevated levels of plasma TC and a LDL-C, though apo E4 and apo E3 have similar binding properties to the apo $\mathrm{B} / \mathrm{E}$ receptor (Weisgraber et al., 1982). It has been shown that apo E4 is catabolized more rapidly than apo E3, possibly resulting in the down-regulation of the liver $\mathrm{LDL}$ receptor and increased levels of plasma LDL (Utermann et al., 1977, 1984; Ehnholm et al., 1984; Gregg et al., 1986; Utermann, 1987; Ordovas et al., 1987). Also, it has been revealed that apo E4 is a major risk factor for late-onset Alzheimer's disease (Corder et al., 1993; Saunders et al., 1993; Poirier et al., 1993; Noguchi et al., 1993; Yoshizawa et al., 1994).

Other minor isoforms have been detected and designated from apo E1 to apo E7 according to the reverse order of mobility of IEF. Apo E5 and E7 were first detected in Japanese patients with hyperlipidemia (Yamamura et al., 1984a, b). Apo E5 is derived from E3 by a Glu $\rightarrow$ Lys substitution at position 3 [(Glu $\rightarrow$ Lys)] (Tajima et al., 1988; Maeda et al., 1989a). Since this type of apo E5 migrates faster than apo E3 on SDS/PAGE, we have tentatively designated it apo E5f. It was recently reported that the receptor binding activity of apo E5f is about twice that of normal apo E (Dong et al., 1990). Apo E5 with the same migration as apo E3 on SDS/PAGE has also been found among Caucasians in the United States (Ordovas et al., 1987). We have tentatively designated it as apo E5s. Further- 
more, a novel apo E5 derived from E3 by a Glu $\rightarrow$ Lys substitution at position 13 $\left[\mathrm{E} 5\left(\mathrm{Glu}_{13} \rightarrow\right.\right.$ Lys $\left.)\right]$ and another novel apo E5 derived from E4 by a Pro $\rightarrow$ Arg substitution at position 84 [E5 $\left(\mathrm{Pro}_{84} \rightarrow \mathrm{Arg}, \mathrm{Cys}_{112} \rightarrow \mathrm{Arg}\right.$ )] were discovered in two FrenchCanadian subjects (Mailly et al., 1991) and in a subject of European descent (Wardell et al., 1991), respectively. On the other hand, Apo E7 is derived from E3 by a $\mathrm{Glu} \rightarrow$ Lys substitution at positions 244 and 245 [E7(Glu 244,245 $\rightarrow$ Lys)] (Maeda et al., 1989b; Tajima et al., 1989). Thus far, apo E7 has been detected only among Japanese (Yamamura et al., 1984a, b; Tsuchiya et al., 1985). As for apo E5 and E7, there are no reports regarding their frequencies and relations with plasma lipid levels in general populations.

The following describes the frequencies of apo E5 and E7 and their relations to the plasma levels of TC, LDL-C, HDL-cholesterol (HDL-C), triglyceride (TG), apo $\mathrm{B}$, and apo $\mathrm{E}$ in 608 apparently healthy Japanese male adults.

\section{MATERIALS AND METHODS}

Subjects were 608 randomly selected apparently healthy Japanese males aged 24 to 65 with a mean age of 47.6 years, who visited the health care center of Kudanzaka hospital in Tokyo for their annual medical examinations. Males with a history of surgery involving the digestive system or those who had been found to have abnormalities of the liver and/or renal functions, or diabetes mellitus at the time of blood sampling were excluded from the investigation. Blood samples were taken after an overnight fast.

Apo $\mathrm{E}$ phenotypes were determined by two-dimensional gel electrophoresis, according to the method of O'Farrell (1975) with a minor modification (Hamaguchi et al., 1982). Briefly, $10 \mu l$ of VLDL-rich fraction was separated from 180 $\mu \mathrm{l}$ of serum by ultracentrifugation for $38 \mathrm{~min}$ at $100,000 \mathrm{rpm}$ using a Beckman TLA-100 rotor. Ampholine mixtures of $1.4 \% \mathrm{pH}$ range $5-8$ and $0.6 \% \mathrm{pH}$ range 3-10 were used in the first-dimensional disc gel. After the two-dimensional gel electrophoresis, the polypeptides were visualized on a slab gel using the silver stain technique of Merril et al. (1981). The apo E spots on the slab gels were confirmed by immuno-blotting (Towbin et al., 1979), using goat anti-human apo E (Dai-ichi, Tokyo) and peroxidase-conjugated rabbit anti-goat IgG (Cappel Laboratories Inc., Malvern, Pa.). This method makes it possible to detect apo E variants with basic pI, such as apo E7.

TC and TG levels were assayed enzymatically. HDL-C levels were measured by the heparin-Ca ${ }^{2+} \mathrm{Ni}^{2+}$ precipitation procedure (Noma et al., 1979). The concentration of LDL-C was calculated according to Friedewald's formula (Friedewald et al., 1972). Apo B and apo E levels were assayed by a single radial immunodiffusion analysis (SRID), (APOE, APOB PLATE, Dai-ichi, Tokyo).

Allele frequencies were estimated by the gene counting method. In-pair differences between apo E phenotypic groups were estimated using Scheffe's procedure 
(parametric test) as well as the Mann-Whitney $\mathrm{U}$ test (nonparametric test). Prior to the statistical analyses, the lipid and lipoprotein traits were adjusted by multiple linear regression for variation in age, height, and weight. For analysis of plasma TG which did not have normal distributions, logarithmic transformation was performed.

\section{RESULTS}

The apo $E$ phenotype distribution and apo $E$ allele frequencies in 608 apparently healthy Japanese males are presented in Table 1. The distribution of the different apo $E$ phenotypes were on the Hardy-Weinberg equilibrium $\left(\chi^{2}=6.73\right.$, $\mathrm{df}=10$, not significant). The frequencies of the $\varepsilon 2$ allele $(0.049)$ and the $\varepsilon 4$ allele $(0.095)$ were significantly decreased and that of the $\varepsilon 3$ allele $(0.841)$ was significantly increased compared with those in most Caucasian populations (Wardell et al., 1982; Menzel et al., 1983; Utermann et al., 1984; Ordovas et al., 1987; Smit et al., 1988). The frequencies of the three common alleles in the Japanese popula-

Table 1. Apo E phenotype and allele frequencies in apparently healthy Japanese males.

\begin{tabular}{cc}
\hline Apo E phenotype & Number $(\%)$ \\
\hline $3 / 3$ & $432(71.1)$ \\
$3 / 4$ & $96(15.8)$ \\
$2 / 3$ & $50(8.2)$ \\
$2 / 4$ & $9(1.5)$ \\
$3 / 7$ & $9(1.5)$ \\
$4 / 4$ & $4(0.7)$ \\
$3 / 5 f$ & $4(0.7)$ \\
$4 / 7$ & $2(0.3)$ \\
$2 / 5 f$ & $1(0.2)$ \\
$4 / 5 \mathrm{~s}$ & $1(0.2)$ \\
$2 / 2$ & $0(0.0)$ \\
\hline Total & 608 \\
\hline Apo E allele & Frequencies \\
\hline$\varepsilon 2$ & 0.049 \\
$\varepsilon 3$ & 0.841 \\
$\varepsilon 4$ & 0.095 \\
$\varepsilon 5 f$ & 0.004 \\
$\varepsilon 5 \mathrm{~s}$ & 0.001 \\
$\varepsilon 7$ & 0.009 \\
\hline & -1
\end{tabular}


tions were not significantly different from those reported by Yamamura et al. 1984a, b), Tsuchiya et al. (1985), and Eto et al. $(1985,1986)$. It is noteworthy that $6(1.0 \%)$ and $11(1.8 \%)$ out of the 608 were found to have apo E5 and apo E7, respectively, in a heterozygous state.

Figure 1 shows examples of the two-dimensional gel electrophoresis patterns

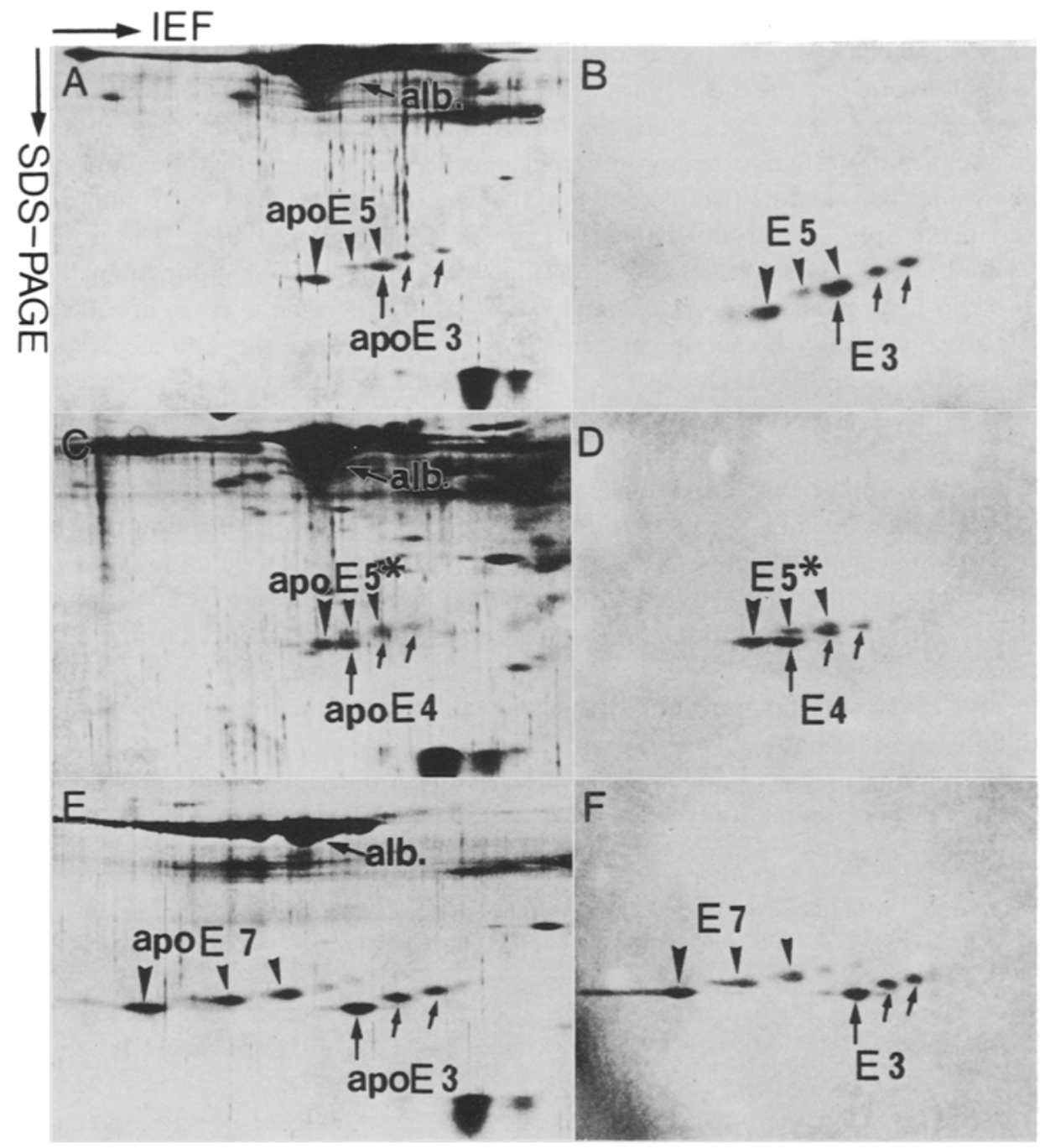

Fig. 1. Two-dimensional gel electrophoresis patterns of the apo E5f, E5s, and E7 phenotypes. A, silver staining of apo E3/5f; B, immuno-blotting of apo E3/5f; C, silver staining of apo E4/5s; D, immuno-blotting of apo E4/5s; E, silver staining of apo E3/7; F, immuno-blotting of apo E3/7. Isoelectric focusing was from left to right and molecular weight separation was from top to bottom. Albumin is shown as "alb." 
of apo E3/5f, apo E4/5s, and apo E3/7 phenotypes, together with the data on the identification of the apo $E$ spot on the gel by immuno-blotting. The frequency of the apo E7 allele was 0.009. As for apo E5, two different isoforms were found: apo E5f with a faster migration than apo E3f (Fig. 1, a and b) on SDS/PAGE, which was detected in five subjects; and apo E5s with the same migration as apo E3 on SDS/PAGE (Fig. 1, c and d), which was observed in one subject with apo E4/5. Most of the apo E5 detected among the Japanese was apo E5f, and its allele frequency was 0.004 . The frequency of the E5s allele was 0.001 .

Table 2 presents the mean plasma TC, LDL-C, HDL-C, and TG, levels among different apo $\mathrm{E}$ phenotypes. Both the total cholesterol and LDL cholesterol levels were significantly different among different apo E phenotypes. In the comparison of the values between the two phenotypes, the average LDL-C level was significantly lower in the apo $E 2 / 3$ group than in the apo $E 3 / 3$ group $(p<0.01)$. The average TC and LDL-C levels were significantly higher in the apo E3/4 group than those in the apo $\mathrm{E} 3 / 3$ group ( $\mathrm{TC}, \mathrm{p}<0.001 ; \mathrm{LDL}-\mathrm{C}, \mathrm{p}<0.01$ ). The average apo $\mathrm{B}$ level was also significantly higher in the apo E3/4 group than in the apo E3/3 group (mean $\pm \mathrm{SD}, 82.9 \pm 20.6 \mathrm{mg} / \mathrm{dl}$ vs. $75.8 \pm 16.1 \mathrm{mg} / \mathrm{dl}, \mathrm{p}<0.001)$. The average apo $B$ level tended to be lower in the apo E2/3 group than the apo E3/3 group (mean \pm $\mathrm{SD}, 70.5 \pm 17.1 \mathrm{mg} / \mathrm{dl}$ vs. $75.8 \pm 16.1 \mathrm{mg} / \mathrm{dl}$ ) but the difference was not significant. The results with the three common phenotypes detected in our samples are in accordance with the data reported thus far (Utermann et al., 1979; Bouthillier et al., 1983; Sing and Davignon, 1985; Eto et al., 1986; Boerwinkle and Utermann, 1988). On the other hand, the average TC and LDL-C levels were lower in the subjects with apo E3/5f and $3 / 7$ than those in the apo E3/3 group, but the differences were not significant. Also the average apo B and apo E levels in the subjects with apo E3/5f and $3 / 7$ were not significantly different from those in the subjects with apo E3/3 (data not shown).

The plasma lipid and apolipoprotein levels of all individuals with apo E5 and E7 found in the present study are shown in Table 3. The only male subject with

Table 2. Mean plasma cholesterol, triglyceride, and HDL-cholesterol levels (in $\mathrm{mg} / \mathrm{dl}$ ) among different apo E phenotypes.

\begin{tabular}{|c|c|c|c|c|c|}
\hline \multicolumn{2}{|c|}{ Phenotype (n) } & \multirow{2}{*}{$\frac{\mathrm{TC}}{181.5 \pm 32.5}$} & \multirow{2}{*}{$\frac{\text { TG }}{136.0 \pm 89.7}$} & \multirow{2}{*}{$\frac{\text { HDL-C }}{47.7 \pm 13.2}$} & \multirow{2}{*}{$\frac{\text { LDL-C }}{106.6 \pm 33.3}$} \\
\hline $2 / 3$ & $(50)$ & & & & \\
\hline $3 / 3$ & $(432)$ & $189.6 \pm 31.4$ & $118.6 \pm 59.1$ & $47.5 \pm 12.5$ & $118.4 \pm 28.6$ \\
\hline $3 / 4$ & $(96)$ & $200.7 \pm 32.0$ & $136.4 \pm 70.7$ & $47.1 \pm 15.6$ & $126.3 \pm 31.1$ \\
\hline $3 / 5 f$ & (4) & $182.0 \pm 30.3$ & $87.8 \pm 24.1$ & $50.6 \pm 5.8$ & $113.9 \pm 26.0$ \\
\hline $3 / 7$ & (9) & $185.3 \pm 28.0$ & $149.2 \pm 61.9$ & $51.6 \pm 14.0$ & $103.9 \pm 23.2$ \\
\hline \multicolumn{2}{|c|}{ Significance } & $\mathrm{p}<0.01$ & not significant & not significant & $p<0.001$ \\
\hline
\end{tabular}

: Level of significance estimated by one-way analysis of variance. 
Table 3. Individual data on subjects with apo E5 and apo E7.

\begin{tabular}{lrrrrrrr}
\hline $\begin{array}{c}\text { Apo E } \\
\text { phenotype }\end{array}$ & $\begin{array}{c}\text { Age } \\
\text { (year) }\end{array}$ & TC & TG & $\begin{array}{l}\text { HDL_C } \\
(\mathrm{mg} / \mathrm{dl})\end{array}$ & LDL-C & Apo B & Apo E \\
\hline 2/5f & 37 & 178 & 188 & 39.6 & 100.7 & ND & ND \\
$3 / 5 \mathrm{f}$ & 41 & 143 & 66 & 49.2 & 80.6 & 52 & 2.8 \\
$3 / 5 \mathrm{f}$ & 51 & 183 & 120 & 44.3 & 114.7 & 73 & 3.0 \\
$3 / 5 \mathrm{f}$ & 43 & 217 & 73 & 58.3 & 144.1 & 108 & 3.9 \\
$3 / 5 \mathrm{f}$ & 36 & 185 & 92 & 50.6 & 116.0 & 83 & 3.5 \\
$4 / 5 \mathrm{~s}$ & 59 & 240 & 98 & 43.3 & 177.1 & $\mathrm{ND}$ & ND \\
$3 / 7$ & 52 & 167 & 139 & 46.9 & 92.3 & 72 & 3.0 \\
$3 / 7$ & 40 & 202 & 88 & 58.6 & 125.8 & 72 & 3.5 \\
$3 / 7$ & 50 & 135 & 136 & 41.9 & 65.9 & 57 & 3.0 \\
$3 / 7$ & 43 & 204 & 164 & 44.6 & 126.6 & ND & ND \\
$3 / 7$ & 59 & 196 & 128 & 46.5 & 123.9 & 83 & 3.2 \\
$3 / 7$ & 39 & 158 & 145 & 39.6 & 89.4 & 72 & 3.2 \\
$2 / 7$ & 53 & 228 & 253 & 47.1 & 130.3 & 104 & 4.7 \\
$3 / 7$ & 48 & 195 & 232 & 53.3 & 95.3 & 88 & 4.9 \\
$3 / 7$ & 36 & 183 & 58 & 85.8 & 85.6 & 52 & 4.4 \\
$4 / 7$ & 40 & 168 & 69 & 38.4 & 115.8 & 78 & 2.6 \\
$4 / 7$ & 44 & 202 & 91 & 41.5 & 142.3 & 83 & 3.3 \\
\hline
\end{tabular}

The average apo $B$ and apo $E$ levels were $75.8 \pm 16.1 \mathrm{mg} / \mathrm{dl}$ and $3.8 \pm 0.8 \mathrm{mg} / \mathrm{dl}$, respectively, in randomly selected 283 subjects with apo E3/3. ND, not determined.

apo E4/E5s was hypercholesterolemic (TC, $240 \mathrm{mg} / \mathrm{dl} ; \mathrm{LDL}-\mathrm{C}, 177.1 \mathrm{mg} / \mathrm{dl}) . \quad$ All individuals with apo E5f or E7 were heterozygotes and their TC levels were less than $230 \mathrm{mg} / \mathrm{dl}$, while 70 out of 608 subjects $(11.5 \%)$ in the present study had cholesterol levels above $230 \mathrm{mg} / \mathrm{dl}$. Plasma apo B and apo E levels were also within normal ranges in all subjects with apo E5f or E7.

\section{DISCUSSION}

The present study confirms racial differences related to three common apo E allele frequencies between Japanese and Caucasian populations (Eto et al., 1986; Hamaguchi et al., 1992). Even if apo E5f and apo E7 were included, apo E variants are less frequent in the Japanese when compared with Caucasian populations. Apo E5f, E5s, and E7, however, were found in $0.9 \%, 0.2 \%$, and $1.8 \%$, respectively, of the subjects, totaling nearly $3 \%$. Following the first detection of apo E5f and apo E7 in Japanese patients with hyperlipidemia (Yamamura et al., 1984a, b), they were observed in apparently healthy Japanese subjects (Tsuchiya et al., 1985; Yanagi et al., 1990). The data obtained in the present study suggests that the occurrence 
of subjects with apo E5 or E7 is not rare and that apo E7 is more common than apo E5 in the Japanese population. The reason why apo E7 is observed in Japanese at a frequency near the polymorphic level remains to be elucidated. One possibility is that a founder effect occurred in Japanese. The other possibility is a difference in the method used to analyze apo E phenotypes. In the present study, a method to detect apo E variants with basic PI, such as apo E7, was used in isoelectric focusing, while conventional isoelectric focusing for the analysis of apo E phenotypes might not detect of apo E7. Further population studies using appropriate methods to detect apo E7 are needed to determine whether apo E7 is present only in Japanese.

The study also shows that all five subjects with apo E5f and all eleven subjects with apo E7 were normocholesterolemic and both groups of subjects with the apo E3/5f genotype or E3/7 genotype had rather decreased average plasma TC and LDL-C levels (Tables 2 and 3). Apo E5f and apo E7 were originally found in patients with hypercholesterolemia (Yamamura et al., 1984a, b). The heterozygote for apo E7 was observed in 2 out of 58 lipid clinic patients $(3.4 \%)$ and 2 out of 69 CCU patients $(2.9 \%$, while the heterozygote for apo E5f was found in 2 out of 58 lipid clinic patients $(3.4 \%)$ and 1 out of $69 \mathrm{CCU}$ patients $(1.4 \%$ ) (Yamamura et al., 1984b). It has been proposed that apo E5 and E7 might increase plasma levels of TC and LDL-C since the average plasma cholesterol levels increase as the net charge of the apo E molecule increases from apo E2 to E4 and apo E5f has two and E7 has four additional positive net charges (Tajima et al., 1989). Individuals with apo E5f and apo E7, however, were also observed among normocholesterolemic populations (Tsuchiya et al., 1985; Yanagi et al., 1990), implying that individuals with apo E5 or those with apo E7 are not always hypercholesterolemic. The results of the present study further indicate that most of the individuals with apo E5f and those with apo E7 are normocholesterolemic at least in the heterozygous state. The data on plasma apo $\mathrm{B}$ and apo $\mathrm{E}$ levels also support this interpretation. Furthermore, the frequencies of heterozygotes for apo E7 (1.8\%) and for apo E5f $(0.9 \%)$ observed in our population were not significantly different from those found in lipid clinic patients by Yamamura et al. (1984b). As for apo E5s, two subjects with apo E3/5s found in the USA (Ordovas et al., 1987) and one with apo E4/5s observed in the present study had elevated TC and LDL-C levels. Whether apo E5s has an effect of elevating TC and LDL-C levels remains to be elucidated.

In conclusion, the results of the present study suggest that apo E5f and E7 are not rare in the Japanese population but, do not cause hypercholesterolemia in most of the heterozygotes.

Acknowledgments We are grateful to Mr. Shiro Abe, Mr. Masaaki Teranishi and Mr. Nobuhiko Shirato, University of Tsukuba, for preparation of the photographs. 


\section{REFERENCES}

Boerwinkle E, Utermann G (1988): Simultaneous effects of apolipoprotein E polymorphism on apolipoprotein E, apolipoprotein B, and cholesterol metabolism. Am J Hum Genet 42: 104 112

Bouthillier D, Sing CF, Davignon J (1983): Apolipoprotein E phenotyping with a single method: application to the study of informative matings. J L.ipid Res 24: 1060-1069

Corder EH, Saunders AM, Strittmatter WJ, Schmechel DE, Gaskell PC, Small GW, Roses AD, Haines JL, Pericak-Vance MA (1993): Gene dose of apolipoprotein E type 4 allele and the risk of Alzheimer's disease in late onset families. Science 261: 921-923

Dong L-M, Yamamura Y, Yamamoto A (1990): Enhanced binding activity of an apolipoprotein E mutant, apo E5, to LDL receptors on human fibroblasts. Biochem Biophys Res Commun 168: 409-414

Eto M, Watanabe K, Ishii K (1985): A rapid flat gel isoelectric focusing method for the determination of apolipoprotein E phenotypes and its application. Clin Chem Acta 149: 21-28

Eto M, Watanabe K, Ishii K (1986): A racial difference in apolipoprotein $E$ allele frequencies between the Japanese and Caucasian populations. Clin Genet 30: 422-427

Ehnholm C, Mahley RW, Chappell DA, Weisgraber KH, Ludwig E, Witztum JL (1984): Role of apolipoprotein $\mathrm{E}$ in the lipolytic conversion of B-very low density lipoproteins to low density lipoproteins in type IJI hyperlipoproteinemia. Proc Natl Acad Sci USA 81: 5566-5570

Friedewald WT, Levy RI, Fredrickson DS (1972); Estimation of the concentration of low-density lipoprotein cholesterol in plasma, without use of the preparative ultracentrifuge. Clin Chem 18: $499-502$

Ghiselli G, Schaefer EJ, Gascon P, Brewer HB Jr (1981): Type III hyperlipoproteinemia associated with apolipoprotein E deficiency. Science 214: 1239-1241

Gregg RE, Zech LA, Schaefer EJ, Brewer HB Jr (1981): Type III hyperlipoproteinemia: Defective metabolism of an abnormal apolipoprotein E. Science 211: 584-586

Gregg RE, Zech LA, Schaefer EJ, Stark D, Wilson D, Brewer HB Jr (1986): Abnormal in vivo metabolism of apolipoprotein E4 in humans. J Clin Invest 78: 815-821

Hamaguchi H, Yamada M, Shibasaki M, Mukai M, Yabe T, Kondo I (1982): Genetic analysis of human lymphocyte proteins by two-dimensional gel electrophoresis: 3. Frequent occurrence of genetic variants in some abundant polypeptides of PHA-stimulated peripheral blood lymphocytes. Hum Genet 62: 142-147

Hamaguchi H, Watanabe Y, Yamanouchi Y, Yanagi H, Arinami T, Miyazaki R, Tsuchiya S, Kobayashi K (1992): Analysis of genes associated with hypercholesterolemia in the Japanese population. In: Roberts DF, Fujiki N, Torizuka K (eds). Isolation, migration and health. Cambridge University Press, New York, pp 154-166

Maeda H, Nakamura H, Kobori S, Okada M, Mori H, Niki H, Ogura T, Hiraga S (1989a): Identification of human apolipoprotein $\mathrm{E}$ variant gene: Apolipoprotein $\mathrm{E} 7\left(\mathrm{Glu}_{244,245} \rightarrow \mathrm{Lys}_{244}, 245\right)^{1}$. J Biochem 105: 51-54

Maeda H, Nakamura H, Kobori S, Okada M, Niki H, Ogura T, Hiraga S (1989b): Molecular cloning of a human apolipoprotein $\mathrm{E}$ variant: $\mathrm{E} 5\left(\mathrm{Glu}_{3} \rightarrow \mathrm{Lys}_{3}\right)^{1}$. J Biochem 105: 491-493

Mahley RW (1988): Apolipoprotein E: Cholesterol transport protein with expanding role in cell biology. Science 240: $622-630$

Mailly F, Xu C, Xhignesse M, Lussier-Cacan S, Talmud PJ, Davignon J, Humphries SE, Nestruchk AC (1991): Characterization of a new apolipoprotein E5 variant detected in two FrenchCanadian subjects. I Lipid Res 32: 613-620

Menzel HJ, Kladetzky RG, Assmann G (1983): Apolipoprotein E polymorphism and coronary

Vol. 39 , No. 3, 1994 
artery disease. Arteriosclerosis 3: 310-315

Merril CR, Goldman D, Sedman SA, Ebert MH (1981): Ultrasensitive stain for proteins in polyacrylamide gels show regional variation in cerebrospinal fluid proteins. Science 211: 14371438

Noguchi S, Murakami K, Yamada N (1993): Apolipoprotein E genotype and Alzheimer's disease. Lancet 342: 737

Noma A, Okabe H, Netsu-Nakayama K, Ueno Y, Shinohara H (1979): Improved method for simultaneous determination of cholesterol in high- and low-density lipoproteins. Clin Chem 25: $1480-1481$

O'Farrell PH (1975): High resolution two-dimensional electrophoresis of proteins. J Biol Chem 250: $4007-4021$

Ordovas JM, Litwack-Klein L, Wilson PWF, Schasefer MM, Schaefer EJ (1987): Apolipoprotein $E$ isoform phenotyping methodology and population frequency with identification of apo El and apo E5 isoforms. J Lipid Res $28: 371-380$

Poirier J, Davignon J, Bouthillier D, Kogan S, Bertrand P, Gauthier S (1993): Apolipoprotein E polymorphism and Alzheimer's disease. Lancet 342: 697-699

Rall SC Jr, Weisgraber KH, Innerarity TL, Mahley RW (1982): Structural basis for receptor binding heterogeneity of apolipoprotein E from type III hyperlipoproteinemic subjects. Proc Natl Acad Sci USA 79: 4694-4700

Saunders AM, Strittmatter WJ, Schmechel D, George-Hyslop PH St, Pericak-Vance MA, Joo SH, Rosi BL, Gusella JF, Crapper-MacLachlan DR, Alberts MJ, Hulette C, Crain B, Goldgaber D, Roses AD (1993): Association of apolipoprotein $\mathrm{E}$ allele $\varepsilon 4$ with late-onset familial and sporadic Alzheimer's disease. Neurology 43: 1467-1472

Sing CE, Davignon J (1985): Role of the apolipoprotein E polymorphism in determining normal plasma lipid and lipoprotein variation. Am J Hum Genet 37: 268-285

Smit M, de Knijff P, Rosseneu M, Bury J, Klasen E, Frants R, Havekes L (1988): Apolipoprotein $\mathrm{E}$ polymorphism in the Netherlands and its effect on plasma lipid and apolipoprotein levels. Hum Genet 80: 287-292

Tajima S, Yamamura T, Yamamoto A (1988): Analysis of apolipoprotein E5 gene from a patient with hyperlipoproteinemia. J Biochem 104: 48-52

Tajima S, Yamamura T, Menju M, Yamamoto A (1989): Analysis of apolipoprotein E7 (apolipoprotein E-Suita) gene from a patient with hyperlipoproteinemia. J Biochem 105: 249-253

Towbin H, Staehelin T, Gordon J (1979): Electrophoretic transfer of proteins from polyacrylamide gels to nitrocellulose sheets: Procedure and some applications. Proc Natl Acad Sci USA 76: $4350-4354$

Tsuchiya S, Yamanonchi Y, Onuki M, Yamakawa K, Miyazaki R, Taya T, Kondo I, Ohnuki M, Hamaguchi $H$ (1985): Frequencies of apolipoprotein E5 and E7 in apparently healthy Japanese. Jpn J Human Genet 30: 271-278

Utermann G, Hees M, Steinmetz A (1977): Polymorphism of apolipoprotein E and occurrence of dysbetalipoproteinemia in man. Nature 269: 604-607

Utermann G, Pruin N, Steinmetz A (1979): Polymorphism of apolipoprotein E. III. Effect of a single polymorphic gene locus on plasma lipid levels in man. Clin Genet 15: 63-72

Utermann G, Hardewig A, Zimmer F (1984): Apolipoprotein E phenotypes in patients with myocardial infarction. Hum Genet $56 ; 237-241$

Utermann G (1987): Apolipoprotein E polymorphism in health and disease. Am Heart J 113: 433440

Wardell MR, Suchlking PA, Janus ED (1982): Genetic variation in human apolipoprotein E. J Lipid Res 23: 1174-1182

Wardell MR, Rall SC Jr, Schaefer EJ, Kane JP, Weisgraber KH (1991): Two apolipoprotein E5 variants illustrate the importance of the position of additional positive charge on receptor- 
binding activity. J Lipid Res 32: 521-528

Weisgraber KH, Innerarity TL, Mahley RW (1982): Abnormal lipoprotein receptor-binding activity of the human $E$ apoprotein due to cystein-arginine interchange at a single site. J Biol Chem 257: 2518-2521

Yamamura Y, Tamamoto A, Hiramori K, Nambu S (1984a): A new isoform of apolipoprotein E-apo E5- associated with hyperlipidemia and atherosclerosis. Atherosclerosis 50: 159-172

Yamamura T, Yamamoto A, Sumiyoshi T, Hiramori K, Nishioeda Y, Nambu S (1984b): New mutants of apolipoprotein $\mathbf{E}$ associated with atherosclerotic disease but not to type III hyperlipoproteinemia. J Clin Invest 74: 1229-1237

Yanagi H, Shimakura Y, Yamanouchi Y, Watanabe Y, Tsuchiya S, Hamaguchi H (1990): Association of hypercholesterolemia and apolipoprotein E4 in school children. Clin Genet 38: 264269

Yoshizawa T, Yamakawa-Kobayashi K, Komatsuzaki Y, Arinami T, Oguni E, Mizusawa H, Shoji $S$, Hamaguchi $H$ (1994): Dose-dependent association of apolipoprotein $E$ allele $\varepsilon 4$ with lateonset sporadic Alzheimer's disease. Ann Neurol (in press) 